\title{
ASPEK SEMIOTIS DALAM PUISI BERTEMA MALAIKAT
}

\author{
Resti Nurfaidah \\ Balai Bahasa Provinsi Jawa Barat
}

\begin{abstract}
ABSTRAK
Malaikat selalu identik dengan kesetiaan, ketaatan, keindahan, kekuatan, dan keanggunan. Malaikat senantiasa diagungkan dan memiliki tempat yang khusus dalam ranah religi sebagai kepanjangan tangan Tuhan. Demikian agungnya makhluk yang diciptakkan Allah dari cahaya itu hingga ditempatkan pada posisi kedua Rukun Iman (dalam agama Islam).

Namun, tidak semua malaikat digambarkan dalam situasi baik. Beberapa penyair di dunia siber mengungkapkan sosok yang berbeda tentang malaikat di dalam karya mereka. Malaikat mengalami metamorfosis yang demikian luas tidak hanya sebagai makhluk ciptaan Tuhan yang paling setia, tetapi lebih sebagai refleksi atas beberapa fenomena yang terjadi di dalam kehidupan nyata. Makalah ini memaparkan mitos malaikat dalam puisi pada beberapa situs pencarian. Analisis pada sumber data dilandasi teori semiotik Roland Barthes, terutama pada sistem pemaknaan sekunder (konotasi dan metabahasa). Sosok malaikat dalam puisi sangat beragam. Malaikat tidak lagi merujuk pada makhluk yang diciptakan Tuhan dari cahaya, tetapi pada manusia dalam berbagai status. Mitos tersebut malaikat dalam puisi juga dapat mengundang reaksi beragam.
\end{abstract}

Kata Kunci: malaikat, puisi, mitos, konotasi, denotasi

\begin{abstract}
Angels are identically connected to these following criteria: loyalty, obedience, beauty, strength, and elegance. Angels are always honored on the religion space. They have a special place in the realm of religions as delegates of the Lord. Based of those reasons, these light based creatures are placed in the second position Pillars of Faith (in Islam).

However, angels are not always be depicted in an good situation. Some cyber poets reveal different figures of angels in their works. Angels suffered such extensive metamorphosis not only as God's most faithful 'staff', but rather as a reflection of several phenomena that occur in the reality. This paper exposes the myth of the Angel in the poem on a few search sites. Analysis of the data below were based on the theory of semiotik Roland Barthes, particularly on the definition of the secondary system ( connotation and metalanguage). Angel myth in poetry is very diverse. Angels no longer refers to beings that created from the light, but humans in different status. There so many reactions of choosing the word 'angle' on the poem.
\end{abstract}

Keywords : angel, poem, myth, connotation, denotation

\section{A. Pendahuluan}

Dalam berbagai budaya dan kepercayaan, malaikat dapat mewujud dalam berbagai bentuk. Jika kita mencari keragaman bentuk malaikat di dunia siber pada beberapa situs pencarian, kita akan mendapati berbagai rupa malaikat, baik bernuansa Eropa Klasik,
Gothic, Oriental (gaya manga), atau Asia, lengkap dengan berbagai ekspresi yang menunjukkan aktivitas yang sedang dilakukan sosok malaikat, misalnya, dalam pandangan Eymann (2002) dan Setiawan (2008), ciri utama dari malaikat secara umum, malaikat memiliki sayap dan dapat terbang dengan sayapnya itu. 
Wujud malaikat sangat beragam terutama dalam dunia sastra. Mitos malaikat kini tidak lagi tertuju pada makhluk religius, tetapi mengalami perluasan pada berbagai sosok, termasuk manusia. Saat ini sosok malaikat cenderung mewujud dalam imajinasi, ekspresi, dan keyakinan manusia (lihat dalam fitur gambar malaikat Google.com). Bentuk malaikat itu tentunya berbeda dengan konsep malaikat dalam konteks kenabian yang menggambarkan sosok malaikat mewujud dan berinteraksi secara langsung dengan para nabi dan rasul dengan seizin Tuhan. Dalam sumber sahih disampaikan bahwa Muhammad saw bertemu muka dengan Jibril as, di antaranya, pada peristiwa turunnya wahyu pertama (lihat Admin dalam bersama dakwah.com diunduh pada tanggal 17 September 2012, pukul 06:20 WIB) dan Isra Mi'raj (lihat Andika. M. dalam Muslim.or.id diunduh pada tanggal 16 September 2012, pukul 09:21 WIB).

Dalam makalah ini, akan dipaparkan wujud malaikat yang hadir di dunia sastra, terutama dalam genre puisi. $\mathrm{Pe} \mathrm{m}$ b a h a s a $\mathrm{n}$ menitikberatkan pada mitos malaikat dalam puisi, yakni perbedaan mitos malaikat dalam puisi yang identik dengan denotasi malaikat dan mitos malaikat dalam realitas. Makalah ini bertujuan untuk menjelaskan bentuk pemaknaan yang mengalami perluasan dalam denotasi dan realitas.

Sumber data dalam penelitian ini merupakan puisi-puisi siber yang dimuat dalam beberapa situs pencarian, di antaranya, (1) chanbumz.blogspot.com (diunduh tanggal 21 Juli 2012), (2) apresiasipuisi.multiply.com (diunduh tanggal 9 Agustus 2012), (3) www. puisi.org (diunduh tanggal 7 Agustus 2012), (4) puisi-iphoel.blogspot.com (diunduh tanggal 7 Agustus 2012), (5) bloodys-bloody.blogspot. com (diunduh tanggal 7 Agustus 2012), (6) fiksi.kompasiana.com (diunduh tanggal 7 Agustus 2012), (7) www.gudangpuisi. com (diunduh tanggal 9 Agustus 2012), (8) id.kemudian.com (diunduh tanggal 21 Juli 2012), dan (9) danalingga.wordpress.com (diunduh tanggal 9 Agustus 2012). Dalam pencarian tersebut, didapati sembilan sampel puisi bertema malaikat, yaitu "Puisi Malaikat
Hatiku" (Chanbum, 2012), "Puisi Mimpi: Malaikat" (Anonim, 2012), "Puisi Sang Malaikat Maut" (Oecoep, 2012), "Puisi Malaikat Maut" (Nov, 2012), "Surat Untuk Malaikat Maut" (Haq, 2005), "Malaikat Surgaku" (Galind56, 2009), "Puisi Malaikat Kecil" (Anonim, 2011), "Malaikat Kecilku" (Febbie, 2009), dan "Puisi Malaikat" (Saeful Badar, 2007).

Untuk menganalisis puisi-puisi tersebut, teori semiotika dikotomi Roland Barthes dipakai sebagai penjelasan dalam analisis, yaitu analisis dalam tataran denotasi dan konotasi. Denotasi merupakan sistem penandaan tingkat pertama, yang terdiri atas penanda (signifient-signifié) dan petanda (signifié). Signifient diubah Barthes menjadi ekspresi (E) sementara itu signifié diubah menjadi isi/ continuum (C). Di antara keduanya, menurut Barthes, terdapat relasi $(R)$ tertentu sehingga dapat terbentuk sign (Sn). Barthes (1986, 89-90) mengatakan bahwa penanda-petanda merupakan hubungan antara materialitas penanda dan konsep abstrak di baliknya. Konotasi merupakan sistem penandaan tingkat dua. Sistem tingkat dua itu terdiri atas konotasi dan metabahasa (mitos). Bartes (1986: 90) Konotasi adalah sebuah sistem yang sebagian ekspresinya terbentuk sendiri dalam sebuah sistem penandaan. Metabahasa adalah suatu sistem yang sebagian besar isinya terbentuk oleh satu sistem tertentu atau sistem yang lain (Bartes, 1986: 90). sistem tersebut merupakan serangkaian semiotik yang memperlakukan satu semiotik. Barthes (1986: 90) memberikan keterangan bahwa jika denotatif terdapat pada tanda dan makna, konotasi dan metabahasa terdapat pada perluasan makna denotatif. Di dalam analisis, pembahasan tentang aspek semiotis dalam puisi bertema malaikat itu terdiri atas pemaknaan kata malaikat melalui sistem primer atau denotasi, serta pemaknaan kata yang sama melalui sistem sekunder berupa mitos.

\section{B. Makna Denotasi Malaikat.}

Makna denotasi dalam semiotika Barthes merujuk pada makna Malaikat dalam KBBI (Alwi, 2005: 705), yakni makhluk Allah yg 
taat, diciptakan dari cahaya, dan mempunyai tugas khusus dari Allah. Keterangan dalam KBBI tersebut sejalan dengan penjelasan Islam tentang malaikat. Islam dan Kristen memiliki pandangan yang sama terhadap malaikat. Dalam sebuah situs Kristen, Christian Answer. net, Eymann (2002) menjelaskan bahwa kata malaikat berasal dari bahasa Yunani (aggelos) dan Ibrani (mal'ak) yang bermakna utusan. Eymann (2002) memberikan definisi malaikat sebagai berikut, yaitu it usually describes the whole range of spirits whom God has created, including both good and evil angels, and special categories such as cherubim, seraphim, and the archangel (Malaikat digambarkan sebagai sekelompok roh yang diciptakan Tuhan, baik atau jahat, termasuk kelompok roh tertentu, seperti cherubim, seraphim, dan the archangel). Dalam Islam, (lihat Admin, 2011 dalam situs http://smpn1pacetkabbandung.blogspot.com yang diunduh tanggal 18 September 2012, pukul 06:40 WIB), kata malaikat berasal dari bahasa Arab malaikah. Kata malaikah merupakan bentuk jamak dari kata malak "kekuatan" dan berasal dari mashdar (kata benda) al-alukah yang bermakna "risalah" atau "misi". Pada perkembangan selanjutnya, pengemban misi disebut ar-rasul.

Malaikat memiliki beberapa ciri berikut. Eymann (2002) dan Setiawan (2008) memberikan ciri: suci (tidak memiliki hawa nafsu), netral (tidak menunjukkan berjenis kelamin tertentu), patuh, tiada berhenti bertasbih dan mendoakan orang yang beriman, dan mampu berubah wujud dengan seizin Tuhan. Salah satu contoh perubahan wujud malaikat pada masa kenabian adalah kehadiran sosok Jibril ketika menemui beberapa nabi dan Rasul dalam wujud seorang laki-laki.

Dalam analisis, makna denotasi malaikat paling jelas terlihat dalam "Puisi Malaikat" karya Saeful Badar. Meskipun dimaknai secara konotatis, ciri fisik malaikat tersebut digambarkan secara eksplisit, yaitu pada serangkaian kata-kata kunci berikut: sayap, makhluk baik, dan wahyu. Pada "Puisi Malaikat Hatiku", meskipun diragukan oleh sang aku lirik, ciri fisik malaikat disebut dalam bait pertama berikut: //malaikat mungkin bersayap, namun kurasa tak juga/ malaikat mungkin tak terlihat, namun kurasa tak juga/ malaikat mungkin begitu sempurna, namun tidak bagiku// (Chanbum: 2012).

\section{Makna Konotasi Malaikat.}

Dalam kitab Injil, kata malaikat juga digunakan untuk menyebut seseorang atau hal-hal lain yang dianggap istimewa dan terhubung dengan unsur 'pembawa pesan'. Eymann (2002) dalam situs Christian Answer. net menyebutkan konotasi malaikat sebagai berikut, yaitu (1) orang biasa yang membawa pesan (Job 1:14; Luke 7:24; 9:52), (2) nabinabi (Isaiah 42:19; Malachi 3:1), (3) imam (Malachi 2:7), (4) pemimpin gereja (Rev 1:20), (5) tiang awan (Exodus 14:19, dan (6) wabah atau penyakit (2 Samuel 24:16-17). Sementara itu, dalam Al-Quran tidak terdapat konotasi untuk kata malaikat.

Berdasarkan hasil analisis yang dilakukan pada kesembilan sumber data makna kata malaikat mengalami pengembangan. "Puisi Malaikat Hatiku" (Chanbum: 2012), berkisah tentang seorang kekasih, baik lelaki atau perempuan (tidak disebutkan secara eksplisit dalam puisi tersebut), yang terpaksa harus melepaskan cintanya demi 'seseorang' lain yang dianggap lebih mumpuni menjadi pasangannya. Sang kekasih memiliki kepribadian istimewa hingga aku lirik menyebutnya sebagai lebih dari 'malaikat'.

Kata malaikat terdapat pada bait pertama, //malaikat mungkin bersayap, namun kurasa tak begitu/ malaikat mungkin tak terlihat, namun kurasa tak juga/ malaikat mungkin begitu sempurna, namun tidak bagiku//. Malaikat pada bait pertama adalah sang kekasih. Malaikat tersebut digambarkan memiliki kriteria berikut, yaitu "bersayap", "tak terlihat", dan "begitu sempurna".

Keikhlasan aku lirik untuk melepaskan kekasihnya itu dilandasi kesadaran bahwa si 'dya' (dia) dianggap memiliki kelebihan yang dapat memberikan kebahagiaan kepada mantan kekasihnya. Kelebihan itulah yang membuat aku lirik memberikan julukan kepada 'dya' dengan gelar 'malaikat' juga, seperti yang terdapat pada kutipan berikut.

"jangan kau risaukan smua yang ada karena ada seseorang yang setia menunggumu disana

yaa, seseorang yang kan menjadi malaikat- 
$\mathrm{mu}$, yang menemanimu sepanjang waktu dan memberikan harapan yang indah untukmu

yakinlah, dan percayalah padanya

karena dya adalah malaikatmu yang selamanya menemanimu"

(Chanburn, 2012)

Di dalam "Puisi Mimpi: Malaikat" (Anonim: 2012), tokoh aku lirik mempertanyakan kapabilitas sang kekasih sebagai calon pendamping hidupnya. Aku lirik mendapat banyak kekecewaan yang luar biasa karena perilaku sang kekasih yang mungkin dulu ia sebut sebagai malaikat. Kekecewaan aku lirik sudah teruraikan pada bait awal sampai bait terkahir. Tiga larik pertama dalam bait pertama, mengungkapkan sifat 'nakal' sang malaikat berikut. Sifat 'nakal' sang malaikat terungkap pada larik / dengan cakarmu engkau mengoyak setiap bunga di tepi jalan/.

\footnotetext{
"senyummu siang tadi tidak mendebarkan berceceran diantara kerumunan peri-peri kecil, dengan cakarmu engkau mengoyak setiap bunga di tepi jalan"

(Anonim, 2012)
}

Dua bait pertama selalu diakhiri dengan pertanyaan-pertanyaan. // benarkah kamu malaikatku?// dan // mungkinkah kamu malaikatku?//. Pada bait ketiga atau terakhir, aku lirik merasa yakin bahwa saat itulah ia harus mengambil keputusan untuk melepas 'malaikat' tersebut dengan pernyataan berikut, // cit..cit..... twit,.twit...... cit..cit..cit...../benar, kamu bukan malaikatku saat kicauan nyata bersahutan pagi ini.// Bunyi suara burung merupakan simbol dari fakta yang harus diterima aku lirik bahwa 'malaikat' tadi tidak bisa menjadi pendamping hidupnya. Aku lirik tidak dapat menggantungkan harapan kepada malaikat dan ia harus membuat keputusan yang cukup berani untuk berpisah dengan lelaki itu. Kesan jantan atau jenis kelamin lelaki pada sang kekasih, terpapar jelas pada bait pertama larik ketiga. Kata cakar dan bunga menyiratkan dua hal yang berlawanan yang dijembatani kata mengoyak. Kata bunga tentu saja merupakan simbol gadis yang menjadi incaran 'burung jantan' yang memiliki cakar.

Pada "Puisi Sang Malaikat Maut" (Oecoep: 2012) wujud malaikat diidentikkan dengan sosok kekasih yang tidak ideal. Sosok malaikat digambarkan dengan pilihan kata yang lugas (sang Malaikat) pada kutipan beberapa larik pertama berikut.

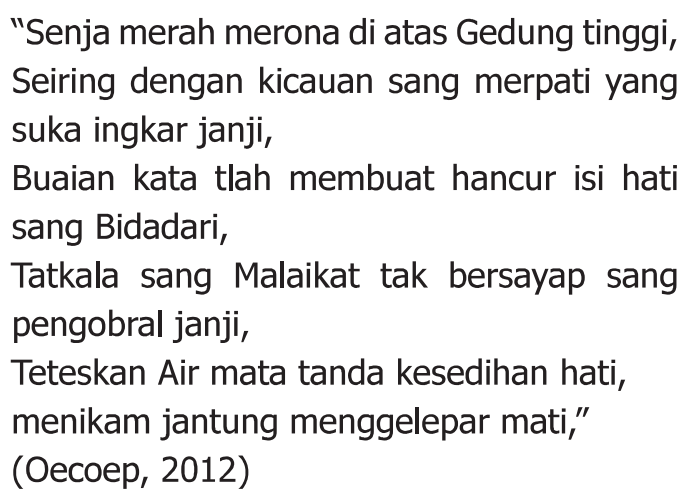

Lelaki yang mendapat julukan 'malaikat tak bersayap' tersebut dianggap sebagai lelaki yang hanya bisa berjanji manis kepada perempuan yang didekatinya. Reaksi dari perempuan yang dikonotasikan sebagai bidadari adalah sakit hati yang dihiperboliskan dengan larik /menikam jantung menggelepar mati/.

Dalam puisi tersebut, aku lirik menghujat si malaikat tak bersayap. Ia juga menyebutkan kata malaikat pada larik ke-15. Kesan sosok lelaki hidung belang semakin ditekankan pada larik tersebut, /padahal engkau orang terlaknat bergaya malaikat/. Malaikat yang dimaksud aku lirik adalah lelaki bertipe flamboyan yang hanya bisa memamerkan keindahan dan kelebihan yang dimilikinya. Namun, jika bidadari tertarik, ia akan memasang jebakan dan menjerumuskan bidadari itu. Saat hal itu terjadi, bidadari akan merasa sakit hati. Sikap si lelaki itu mendapat hujatan sangat tajam baik dari aku lirik (mungkin aku lirik pernah menjadi korban). Pada larik ke-17 terdapat hujatan berikut, /Lagakmu seperti bedebah bangsat/. Hujatan yang hiperbolis itu mengusung dua kata bedebah dan bangsat. Penggunaan kedua kata itu menunjukkan tingkat kemarahan yang sangat tinggi.

Puisi tersebut diakhiri dengan barisan larik yang mengusung nasihat agar si malaikat tadi menghentikan aksinya dan segera 
bertobat. Nasihat tersebut terdapat dalam kutipan berikut.

"janganlah berjudi dengan umur isilah hidupmu dengan tafakur jangan menunggu jika usiamu sudah uzur atau menunggu gajah bertelur karena hidup itu mesti bersyukur" (Oecoep:2012)

Kejamnya malaikat juga terdapat pada "Puisi Malaikat Maut" (Nov: 2012). Nov menggambarkan satu peristiwa pembunuhan yang terkesan blak-blakan. Puisi diawali dengan barisan kata yang menggambarkan situasi sesaat sebelum peristiwa tersebut terjadi.

"Gelap..

Sepi..

Sunyi..

Angin bertiup dingin..

Menggoyang pohon cempaka beringin

Sshhh.. sshhh..."

(Nov:2012)

Suasana mencekam tersebut tersambung dengan peristiwa pembunuhan yang digambarkan dengan vulgar. Pembunuh tidak berkata atau membuat tindakan awal, tetapi langsung menghujamkan senjata yang ia miliki kepada korbannya. Kesan kejamnya si pembunuh sesungguhnya terdapat larik dua terakhir. Kata malaikat hanya digunakan sebagai judul saja. Sementara itu, larik kedua terakhir merupakan penegasan tugas si malaikat sebagai pembunuh berikut. / Makhluk jubah hitam itu pun pergi/. Nov menegaskan suasana kelam peristiwa pembunuhan itu dengan meyebut warna kostum yang digunakan sang malaikatul maut. Namun, puisi itu diakhiri dengan vonis pasti kepada para pelaku kejahatan, yaitu neraka dalam kutipan larik terakhir berikut. / Menuju pintu neraka yang terbuka pasti//.

Amarah dan gugatan atas sebuah peristiwa kematian juga terdapat pada puisi yang berjudul "Surat Untuk Malaikat Maut" (Haq: 2005). Puisi tersebut dipersembahkan kepada sang penguasa yang hingga saat ini tidak berani mengungkapkan siapa dalang pembunuhan salah seorang tokoh LSM itu. Sikap 'pihak berwenang' dan 'bertanggung jawab' atas peristiwa kematian Munir tersebut diungkapkan dalam kutipan bait pertama dan kelima berikut.

"Wahai malaikat kematian yang bertahta di kegelapan

Kenapa tak lagi kau cabut nyawa kawankawan kami??

Mengapa kau mengunci diri di balik jeruji keterasingan

Berdiam diri dan malas bekerja.

$[\ldots]$

Kenapa kau tutup wajahmu

Ketika suatu saat di tepi sebuah sungai tak bernama

Kita duduk menghadap ke sebuah tebing berwarna jelata

Tubuhmu gemetar ketika kusebutkan nama seorang kawan"

(Haq, 2005)

Pihak-pihak terkait pembunuhan Munir tersebut disebut sebagai malaikat kematian. Namun, malaikat itu hanya berani 'bersikap kejam' pada satu waktu saja, tetapi tidak mau bertanggung jawab. Hal itu digambarkan dengan peribahasa bertahta di kegelapan dan di tepi sebuah sungai tak bernama. Kedua penggalan larik tersebut menyiratkan bahwa si pembunuh memiliki sifat pengecut.

Puisi tersebut diakhiri dengan sederet pertanyaan serta kalimat pernyataan bahwa para pendukung mendiang Munir tidak akan berhenti sampai kapan pun. Hal itu terdapat dalam kutipan berikut.

"Merasa berdosakah kamu atas perbuatanmu setahun silam?

Kenapa kau lakukan dengan curang? Kenapa tidak dengan tangan mu sendiri? 
Kenapa harus lewat makanan dari orangorang suruhan?

Takutkah kamu??

Sepengecut itukah kau?

Jawab!!!! hai kau yang memegang setiap nyawa manusia!!

Sebab kini kami tak takut lagi, sebab kini kami menantangmu!!"

(Haq: 2005)

Hujatan dalam kutipan itu bukan hanya ditujukan pada kasus Munir, tetapi pada sederet kasus serupa yang tidak pernah terselesaikan. Bait terakhir menunjukkan bukti dalamnya rasa duka, kecewa, sedih kelompok marginal yang dibela Munir semasa hidupnya. Lebih jauh lagi, hal itu juga merupakan kemarahan sebagian rakyat Indonesia yang selama ini hak-hak mereka terabaikan. Penguasa keji dalam puisi Haq tersebut digelari malaikat kematian.

"Malaikat Surgaku" (Galind56, 2009) sangat berbeda dengan arah kedelapan puisi lain. Malaikat surgaku ditujukan kepada sosok ibu yang sangat berkesan dalam diri. Aku yang kini telah dewasa mengenang kembali masa-masa dulu bersama sang ibu. Saat berada dalam kandungan digambarkan secara metaforis dalam kutipan berikut.

"ia yang dulu berbagi nafas denganku.. sampai sekarang tetap begitu.

ia yang dulu berbagi raga denganku.. sampai sekarang kita menyatu..

ia yang dulu berbagi lelah denganku.. ketika ini ia tak mau..

ia yang dulu berbagi nyawa denganku.. ketika ini ia tak ragu.."

(Galind56, 2009)

Puisi tersebut sarat pujian saat sang ibu bertindak sebagai perisai di masa pertumbuhan. Kelak setelah dewasa, aku lirik merasa bingung karena tidak pernah mampu mencari kata sepadan yang dapat ia berikan sebagai penghargaan kepada sosok agung itu. Pujian spontan terlontar pada bait ke tujuh berikut.

"mungkin selama ini..

aku diam.. karena memang tak ada kata yang sepadan untuk mu..

kau..

kau..

adalah superior!!!

karena perasaan mu merobek bahasa..

tak kenal usia.."

(Galind56: 2009)

Sementara puncak penghargaan aku lirik terhadap sang ibu terdapat pada bagian penutup puisi tersebut, yaitu / untuk ibuku../ malaikat yang nyata bagiku..//. Dalam puisi tersebut, aku lirik telah dapat membuktikan sebuah pepatah yang berbunyi kasih ibu sepanjang jalan, kasih anak sepanjang galah. Perjuangan sebagai seorang ibu tidaklah mudah karena perjalanan mendidik dan membesarkan buah keturunan demikian rumit. Puisi tersebut memberikan penekanan kepada pembaca bahwa menjadi seorang calon ibu tidak mudah. Untuk itu, ia wajib mempersiapkan diri dengan bekal yang cukup demi mewujudkan peranan utamanya tersebut.

Puisi tersebut dapat digolongkan pada puisi religi. Beberapa bait mengungkapkan tahapan perjalanan sebuah ruh ketika hendak ditiupkan. Beberapa keterangan sahih memberikan paparan tentang dialog antara ruh dan Sang Pencipta sebelum ditiupkan ke dalam rahim. Setelah berdialog panjang, akhirnya ruh bersedia untuk diturunkan ke bumi karena dijanjikan akan bertemu malaikat serupa dengan malaikat yang selalu menjaganya di alam ruh (Ghozali, 2009). Aku lirik mendapati malaikat di dunia nyata, yaitu ibu.

Dua puisi berikut "Puisi Malaikat Kecil" (Anonim, 2011) dan "Malaikat Kecilku" (Febbie, 2009), berisi pujian kepada malaikat kecil, sebutan lain untuk anak. Sebutan malaikat kecil terlontar jelas di setiap puisi. Sebutan malaikat kecil dilandasi kelucuan dan kepolosan si anak. Di dalam kedua puisi itu terdapat nilai yang sama, yaitu cita-cita dan harapan yang tinggi sang bunda kepada anaknya. Kedua puisi itu juga dilandasi salah satu hadist Nabi yang mengibaratkan anak itu selembar kain putih dan kedua orangtuanyalah yang menjadikannya Nasrani, Yahudi, dan 
Majusi (HR Baihaqi dalam Rofiqlia77, 2010). Kesan suci pada anak tersebut diungkapkan Anonim dengan ungkapan hatimu yang putih, sementara Febbie dengan ungkapan yang tanpa dosa.

Puisi terakhir bertema malaikat berjudul "Puisi Malaikat" (Saeful Badar, 2007). Puisi tersebut sempat menggemparkan dunia pers Jawa Barat sehingga menimbulkan dampak yang cukup luas.

\author{
"Metang-mentang punya sayap \\ Malaikat begitu nyinyir dan cerewet \\ Ia berlagak sebagai makhluk baik \\ Tapi juga galak dan usil \\ Ia meniup-niupkan wahyu \\ Dan maut \\ Ke saban penjuru" \\ (Malaikat, Badar: 2007)
}

Kata malaikat di dalam puisi tersebut dihubungkan dengan satu frasa yang menjadi ciri fisik makhluk tersebut, yaitu punya sayap. Makna kata malaikat mengalami pengembangan luas jika dihubungkan dengan diksi lainnya yang berkonotasi negatif, seperti: begitu nyinyir dan cerewet, berlagak sebagai makhluk baik, galak dan usil, serta meniupniupkan wahyu, serta dan maut. Puisi tersebut terkait kebiasaan pihak-pihak berwenang di negeri ini yang sering bertindak semena-mena demi kepentingannya sendiri. Di dalam fakta, Saeful Badar menyaksikan dan merasakan sendiri dampak tindakan 'pihak-pihak yang punya kuasa' tersebut.

Jika kata malaikat terkait dengan makna pihak yang berwenang, kata sayap dalam puisi tersebut terkait makna kuasa. Dengan alat kuasa yang utama tersebut, pihak berkewenangan tadi dapat dengan mudah menaklukan kelompok yang 'sekadar ingin menikmati kehidupan'. Di dalam realitas, jika kuasa itu dikaitkan dengan peristiwa pemilihan kepala daerah atau pilkada, kata malaikat dapat dikembangkan sebagai calon pemimpin daerah yang giat berebut perhatian dan suara calon pemilihnya sebanyak mungkin. Cara apa saja ditempuh para kandidat untuk meraup keuntungan pribadi. Janji manis (diwakili kata wahyu) dan 'tekanan' kepada publik pun seakan menjadi menu biasa meskipun dengan kemungkinan besar hal itu akan segera terwujud jika si kandidat kelak terpilih. Jika tidak terpilih, tidak jarang para kandidat berani menarik kembali pemberiannya. Banyak rakyat tertipu dengan topeng ramah dan indah sang kandidat atau penguasa ketika mereka membutuhkan dukungan masyarakat. Namun, seringkali rakyat dibuat kecewa dengan 'kealpaan' kandidat terpilih saat memegang jabatan yang diidamkannya itu. Kata maut menandakan bahwa tindakan sang penguasa tersebut sering membahayakan dan menjurumuskan rakyat kecil.

"Puisi Malaikat" pernah dimuat di suplemen "Khazanah", Pikiran Rakyat, edisi 4 Agustus 2007. Tidak lama sesudah pemuatan puisi tersebut, pihak yang tersinggung, di antaranya Dewan Dakwah Islamiyah Indonesia Jawa Barat mengajukan somasi kepada Pikiran Rakyat. Pada tanggal 6 Agustus 2007, redaksi memuat berita pembatalan pemuatan puisi tersebut. Sementara itu, Redaktur Khazanah saat itu, Rahim Asyik Fajar A. diberhentikan secara resmi sejak tanggal 11 Agustus 2007 dari jabatannya tersebut. Saeful Badar, sebagai penulis, juga tidak luput dari paksaan dan tekanan untuk menyatakan permohonan maaf di media yang sama.

Peristiwa tersebut menuai semarak suara pro dan kontra di dunia maya. Beberapa situs (danalingga.wordpress.com, beritaseni. wordpress.com, sawali. wordpress. com, blogajibandung. wordpress.com) memuat suara dukungan sampai penyataan bersama komunitas sastra se-Jabar terhadap ketidakadilan dan perampasan kebebasan berekspresi tersebut. Berbagai dukungan tersebut mendapatkan sambutan yang luar biasa dari para pecinta sastra maupun nonsastra. Mereka menganggap bahwa tindakan somasi oleh beberapa ormas Islam, terutama DDII tadi, merupakan tindakan pemaknaan yang keliru. Para sastrawan bersikukuh bahwa mereka tidak menemukan bagian puisi yang menghina akidah. Namun, karena kuatnya tekanan dari pihak-pihak yang merasa tertusuk dengan puisi tersebut, media kebanggaan Jawa Barat itu seolah tidak berkutik dalam mengha- 
dapi dominasi. Demi kepentingan jangka panjang, Pikiran Rakyat akhirnya mengalah.

"Puisi Malaikat" cukup lugas dalam menyampaikan pesan tentang peristiwa yang sering terjadi di negeri ini. Kelugasan itu mengundang somasi oleh beberapa ormas Islam tersebut selain menuai tekanan dan teror luar biasa kepada penulis dan pihak media yang memuat puisi itu. Namun, di sisi lain, somasi itu mendatangkan keuntungan sendiri kepada penulis. Badar tanpa disadari telah membuka peluang bagi para simpatisan untuk berekspresi dengan leluasa pada beberapa situs. "Puisi Malaikat" mendapati beberapa berupa puisi sekuel berikut.

\section{PENYAIR}

"Mentang-mentang punya pena

Penyair begitu nyinyir dan cerewet

Ia berlagak sebagai makhluk bebas

Tapi juga melenakan dan usil

Ia meniup-niupkan protes

Dan kebebasan yang bablas

Ke saban penjuru.

(maap tapi saya bukan ulama)"

(Irwan, 2007)

\section{BLOGGER}

"Mentang-mentang punya keyboard Blogger begitu nyinyir dan cerewet

Ia berlagak sebagai makhluk kritis

Padahal gak punya kuasa apa apa, kalah

kuasa dia

Ia kerap meniup niupkan protes

Ke saban penjuru."

(Mrs. Neo Forty-Nine, 2007)

\section{MALAIKAT}

"Mentang-mentang punya moral

Malaikat begitu manis dan baik hati

Ia berlagak sebagai makhluk yang kejam

Tapi cuma pura-pura dan gak serius

Ia meniup niupkan cinta

Dan kasih sayang

Ke saban penjuru."

(Raka, August 07)
Puisi berjudul "Penyair" dan "Blogger" merupakan puisi sekuel yang menunjukkan sikap kontra penyair kepada Saeful Badar. Puisi tersebut menyindir Badar pada kecerobohan badar sebagai seorang penyair. Di dalam puisi "Blogger" terdapat sindiran keras kepada para pengunggah tanggapan puisi Badar. Mrs. Neo Forty-Nine dalam puisi itu menyindir bahwa para penanggap hanya banyak bicara. Ia berpendapat bahwa suara para blogger itu tidak akan ditanggapi pihak berwenang. Puisi "Malaikat" menunjukkan pemaknaan kata malaikat lebih luas. Kata malaikat di dalam puisi itu ditujukan kepada pihak berwenang yang kerapkali menunjukkan sikap munafik. Untuk menunjukkan wibawa, mereka bersikap keras. Namun, sebenarnya mereka lemah. Selain ketiga puisi sekuel tadi, Badar juga mendapatkan dukungan lain berupa dua puisi tanpa judul berikut.

"Ah.... para malaikat

Ternyata engkau memang tiada kerjaan

Sampai sibuk meributkan

Sebuah sajak dari seorang seniman

Yang coba menggambarkanmu apa adanya"

(Danalingga, 2007)

"Duhai Para Malikat...

Mengapa beringsut dengan protes

Bukankah ada sebab yg kuat, untuk mengalihkan pandang

Lakukan saja, jika titah telah dititah.. Tanpa kompromi tanpa pandang bulu...

Duhai Para Malaikat...

Sang Penitah, menetapkan sesuai rencana yg tetap

akan berguna bagi pencari kebenaran murni...

jangan masgul, jangan bersedih...

Sang Penitah sangat tahu dari apa yg tidak kau ketahui... Duhai Para Malaikat...

Jangankan terberangusnya sebuah puisi tsunami bahkan memberangus dunia, dan dibangun dengan yg lebih baik maka beroleh kebahagiaanlah yg diberi 
kebahagiaan...

lalu lupa akan yg pernah terjadi...

demikian terus sampai sadarnya... beroleh bahagia dengan kekalnya...

Duhai Para Malaikat...

mengapa murungmu tak sudah-sudah... bukannya janjiNYA sudah dipenuhi... mana senyummu yg indah itu... mana kepakan sayap cahayamu itu... ayo kepakkan..kepakkan penuhi hatiku dengan cahaya...

agar gelap tak membodohiku..." (Zal, 2007)

Kedua puisi tanpa judul itu menunjukkan simpati dan empati kepada Badar serta antipasti kepada pihak-pihak berwenang yang dianggap suka mempermalahkan hal sepele. Kedua penyair itu, Danalingga dan Zal, menyarankan pihak berwenang untuk lebih mengutamakan penyelesaian persoalan primer dalam masyarakat. Dukungan lain untuk Badar dari para penanggap kebanyakan berupa komentar. Beberapa komunitas sastra se-Indonesia membuat surat penyataan bersama. Puisi bagi penggiat komunitas sastra, di antaranya, Alwi (2007) menjadi ajang pemaknaan luas dan terbuka, bukan ajang untuk pengajuan kepentingan kebenaran interpretasi sendiri, termasuk penyair. Perdebatan panjang "Puisi Malaikat" tersebut menjadi bukti bahwa ambiguitas di negeri ini masih kental. Di satu sisi, kebebasan berekspresi dan kebebasan pers diumbar ke permukaan. Namun, jika suara penyair dianggap pedas akan mengundang sangsi, seperti dialami Badar.

\section{Simpulan}

Berdasarkan hasil analisis, pemaknaan sosok malaikat dalam puisi terdiri atas denotasi dan konotasi. Makna denotasi malaikat di dalam puisi disebutkan hanya pada tataran ciri fisik saja, yaitu memiliki sayap, tidak terlihat, dan bertugas menyampaikan wahyu. Denotasi malaikat di dalam puisi tidak dominan. Berbeda dengan denotasi, makna konotasi tentang malaikat sangat mendominasi. Malaikat dalam konteks konotasi mengalami pengembangan hampir tanpa batas. Malaikat tidak lagi merujuk pada makhluk ciptaan Tuhan, tetapi meluas pada sosok manusia, di antaranya kekasih, ibu, anak, penguasa, dan penjahat.

Hasil analisis juga menunjukkan bahwa malaikat tidak lagi dipresentasikan sebagai simbol kepatuhan, seperti pada sosok kekasih, ibu, dan buah hati yang mampu memberikan kesan sangat dalam bagi penulisnya. Malaikat, pada sisi lain, digambarkan sebagai biang keladi atas berbagai peristiwa yang tidak menyenangkan atau mengerikan. Diksi malaikat digunakan sebagai simbol kemudahan atas sebuah perilaku (manusia) di dalam realitas, baik pada perilaku yang menyenangkan atau yang tidak menyenangkan. Selain itu, diksi malaikat di dalam sumber data cenderung dijadikan alat pencitraan manusia.

Penggunaan diksi malaikat di dalam puisi, tidak hanya menunjukkan perluasan makna, tetapi mengundang reaksi. "Puisi Malaikat" karya Saeful Badar mendapatkan dampak berupa reaksi keras dari berbagai pihak, terutama lembaga-lembaga Islam dan simpatisan pro-lembaga itu. "Puisi Malaikat" dianggap sebagai sindiran keras terhadap pihak berwenang. Hal itu mengundang reaksi negatif yang diterima penulis dan media yang memuat puisi itu. Peristiwa itu, pada satu sisi, menjadi sumber inspirasi bagi simpatisan "Puisi Malaikat". Dukungan dan hujatan bermunculan silih berganti pascapemuatan puisi tersebut dari berbagai kalangan, baik berupa tanggapan, puisi sekuel, maupun puisi baru. 


\section{Daftar Pustaka}

Admin. 2011. "Etimologi Nama dan Tugas Para Malaikat" dalam http://smpn1pacetkabbandung.blogspot.com/2011/08/etimologi-nama-dan-tugas-para-malaikat.html diunduh tanggal 18 September 2012, pukul 06:40 WIB.

Alwi, Hasan. 2005. Kamus Besar Bahasa Indonesia. Jakarta: Balai Pustaka.

Alwi, Ahmad Syubbanuddin. 2007. "Membaca atas Nama Tuhan" dalam http://www.commongroundnews.org/article.php?id=21684\&lan=ba\&sp=0 diunduh tanggal 9 Agustus 2012, pukul 11:12 WIB.

Anonim. 2012. "Puisi Mimpi: Malaikat" dalam http://id.kemudian.com/node/255186 diunduh tanggal 21 Juli 2012, pukul 14:28 WIB.

Badar, Saeful. 2007. "Puisi Malaikat" dalam http://danalingga.wordpress.com/2007/08/16/ sajak-protes-kepada-malaikat/ diunduh tanggal 9 Agustus 2012 pukul 10.30 WIB.

Barthes, Roland. 1986. Elements of Semiology. New York: Hill and Wang.

Chanbum. 2012. "Puisi Malaikat Hatiku" dalam http://chanbumz.blogspot.com/2012/04/ puisi-malaikat-hatiku.html diunduh tanggal 21 Juli 2012, pukul 14:27 WIB.

Danalingga. 2007. Puisi dalam http://danalingga.wordpress.com/2007/08/16/sajak-proteskepada-malaikat/ diunduh tanggal 9 Agustus 2012 pukul 10.30 WIB.

Eymann, Paul. 2002. "Siapa dan Apa Malaikat itu?", artikel mini dalam http://christiananswers.net/indonesian/q-acb/acb-t005i.html diunduh tanggal 12 Agustus 2012, pukul 12:14 WIB.

Febbie. 2009. "Malaikat Kecilku" dalam http://apresiasipuisi.multiply.com/journal/item/3585/ Malaikat-kecilku?\&show_interstitial=1\&u=\%2Fjournal\%2Fitem diunduh tanggal 9 Agustus 2012 pukul 10.23 WIB.

Galind56. 2009. "Malaikat Surgaku" dalam http://www.puisi.org/2009/09/01/malaikat-surgaku/ diunduh tanggal 7 Agustus 2012, pukul 10.14 WIB.

Haq, Saiful. 2005. "Surat Untuk Malaikat Maut" dalam http://puisi-iphoel.blogspot. com/2007/02/surat-untuk-malaikat-maut.html diunduh tanggal 7 Agustus 2012, pukul 10.13 WIB.

Mrs. Neo Forty-Nine. 2007. "Puisi Malaikat" dalam Hikayat berjudul "Surat Terbuka Mengenai Kasus Sajak Malaikat" dalam http://commonroom.info/2007/surat-terbuka-mengenai-kasus-sajak-malaikat/ diunduh tanggal 7 Agustus 2012, pukul 10.15WIB.

Nov, Agung. 2012. "Puisi Malaikat Maut" dalam http://bloodys-bloody.blogspot. com/2012/03/puisi-malaikat-maut.html diunduh tanggal 7 Agustus 2012, pukul 10.00 WIB.

Oecoep, Adi. 2012. "Puisi Sang Malaikat Maut" http://fiksi.kompasiana.com/puisi/2012/02/28/puisi-sang-malaikat-maut/ diunduh tanggal 7 Agustus 2012, pukul 10.00 WIB.

Raka. 2007. "Malaikat" dalam Hikayat berjudul "Surat Terbuka Mengenai Kasus Sajak Malaikat" dalam http://commonroom.info/2007/surat-terbuka-mengenai-kasus-sajak-malaikat/ diunduh tanggal 7 Agustus 2012, pukul 10.15WIB.

Rofiqlia77. 2010. "Beberapa Hadist Rasulullah SAW tentang Pendidikan anak" dalam http:// khalifahindonesia.wordpress.com/2010/06/02/beberapa-hadits-rasulullah-saw-tentangpendidikan-anak/ diunduh tanggal 13 Agustus 2012, pukul 01.19 WIB.

Setiawan, Maramis. 2008. "Penjelasan Rukun Iman (2): Iman Kepada Malaikat Allah" dalam http://maramissetiawan.wordpress.com/2008/04/25/penjelasan-rukun-iman-2-imankepada-malaikat-allah/ diunduh tanggal 12 Agustus 2012, pukul 12:16 WIB.

Zal. 2007. Puisi dalam http://danalingga.wordpress.com/2007/08/16/sajak-protes-kepadamalaikat/ diunduh tanggal 9 Agustus 2012 pukul 10.30 WIB. 